\title{
MASTERING AGTECH AGAIN: EMERGING OF NEW TRAINING OFFERS AND INTERMEDIATE PLAYERS
}

\begin{abstract}
Davide RIZZO, UniLaSalle, Chair in Agricultural Machinery and New Technologies - InTerACT UP 2018.C102, 19 rue Pierre Waguet, F-60000 Beauvais, France, davide.rizzo@unilasalle.fr (corresponding author)

Simon RITZ, UniLaSalle, Chair in Agricultural Machinery and New Technologies, 19 rue Pierre Waguet, F-60000 Beauvais, France, simon.ritz@unilasalle.fr

Anne COMBAUD, UniLaSalle, InTerACT UP 2018.C10219 rue Pierre Waguet, F-60000 Beauvais, France, anne.combaud@unilasalle.fr

Agricultural machinery manufacturers historically referred to the intermediate players for selling, maintenance, customer service and/or training of equipment appear to interact with farmers and end-users. Intermediate players have therefore faced the burden to master the technology, in constant evolution, and the associated training needs at the interface between a sophisticated equipment and the enduser and its sociological characteristics (age, education, background, etc.). However, the effective deployment of agricultural technologies data augmented equipment demands well trained players. How to ensure that the intermediate players have the required skills to integrate the use of agtech in the farm? This paper will discuss the role of educational and ongoing vocational training for the mastery of agtech. We will start from a comparative review of some key national and European technical reports in the agricultural equipment and innovation domains. On these bases, we will focus on France to describe the role of intermediate players of the agricultural equipment sector to realize their agricultural and digital transitions.
\end{abstract}

Keywords. higher education, technical education, smart farming, agricultural data, Europe, France

\section{INTRODUCTION}

Agricultural technologies (agtech in short) are considered in this text as the available tools ranging from classical farming machinery and implements to the wealth of data capturing devices increasingly used to inform decision support and farming management systems. Connection and automation are the cutting-edge of agtech that allow for collecting and managing data, (feeding big-data) new tools for fine-tuning farmers' decision making and to monitor the environmental footprint of agriculture. Agtech is generally related to other definitions like precision farming (i.e., the availability of positioning systems for variable rate application) and "farming 4.0 " that is the way beyond machinery towards augmented data-driven agriculture. To be noticed, precision agriculture is one of the twenty technologies that are expected to change our lives in the near future according to a couple of reports addressed to the Members and staff of the European Parliament (Kurrer and Tarlton, 2017). Indeed, it is the only related to agriculture. Altogether, agtech could be meant as the growing pool of cyber-physic interfaces meant to enhance farming and make smarter decisions (Lioutas et al., 2019). This short paper aims to provide an overview of the multiple, sometimes contrasting, perspectives on agtech players and their role in the emerging of new training offers and intermediate players. Based on a comparative reading of selected official institutional documents we will draw some challenges for education and training with a focus on France.

\section{AGTECH INTERMEDIATE PLAYERS: ROLES AND CHALLENGES}

We include in the agtech players the farmers and the other farming actors, as well as the various providers of farming equipment and services. Historically, they include manufacturers and dealers, though new players are emerging due to the development and proposal of agricultural offers from actors external to the agricultural sectors (Dubois et al., 2019). The Agriculture and Rural Development Department of the European Commission indicates that the next Common Agricultural Policy will orient the use of agtech to enable a whole-farm management approach. This will include using information technology, satellite positioning data, remote sensing and proximal data gathering, with the goal to optimize returns on inputs whilst potentially reducing environmental impacts. Special helps will be provided for small and mediumsized farms to join the digital farming revolution (DG Agri, 2017).

On the one hand, sensors and management software are being adopted in agriculture to improve traceability and to enable the performance monitoring (Figure 1). In a way, these could help farmers to meet the societal conflicting expectations to reduce pressure on environmental resources while delivering safe food for a growing population (Kritikos, 2017). On top of that, a structural renewal of the farmers' generation is predictable in the upcoming years due to the combined effect of the ageing of the current farmers and the improvement of the educational and training level of the new 
ones. The population pyramid for the European Union shows that the dominant class is of farmers of 65 years or more, representing over $20 \%$ of the farmers population in 2016 (Cook et al., 2018, p. 25). However, the educational attainment of the working agricultural population are quite heterogeneous across the Member States (Eurostat, 2017).

On the other hand, agtech are still evolving to provide real-time data and high-precision positioning that are feeding more complex decision support systems and, eventually, enabling new farming models (Philippe David et al., 2016; World Economic Forum, 2018). The farming operators and early adopters are making clear that to deploy the full potential of the cutting-edge of agtech and data-augmented agriculture there is the need for new skills, adapted agronomic references and more integrated knowledge.

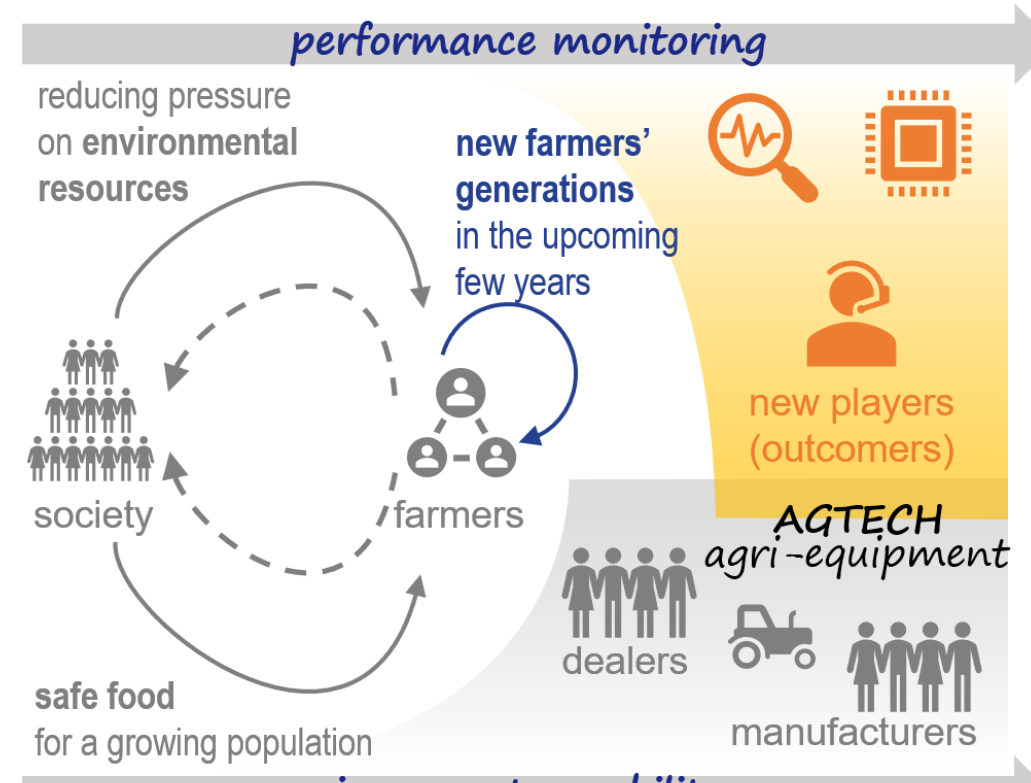

improve traceability
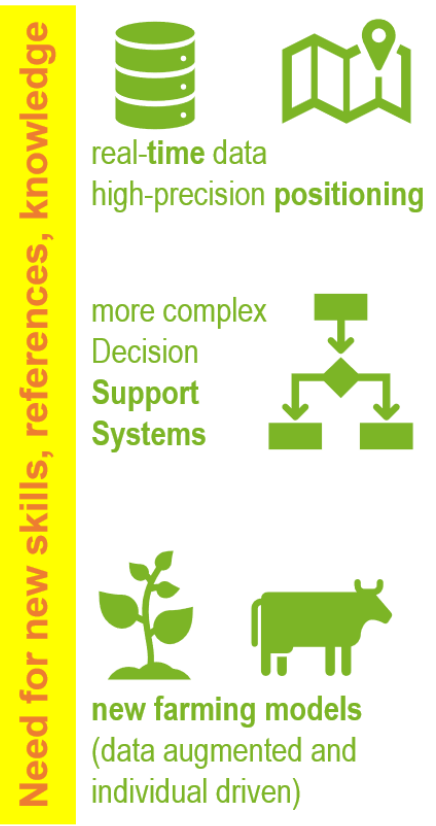

real-time data

high-precision positioning
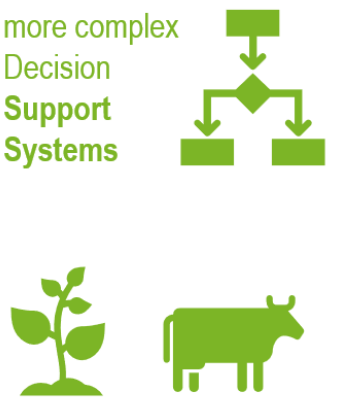

new farming models

(data augmented and individual driven)

Figure 1. Simplified summary of the key actors in the agtech and agricultural equipment sector and of the emerging opportunities coming from the advances in agricultural related technologies.

Altogether, the renewal of the farmers' population and the incoming of new providers of agtech solutions highlight the crucial roles of intermediate players in easing the mastery and exploitation of the full potential of data-augmented equipment. Yet, some of the key stakeholders in this sector in Europe depict different visions.

In their prospective document about the future of European agriculture, the representatives of farmers and agricooperatives express the need for increasing the range of knowledge to master the multiple emerging solutions for precision agriculture. The document calls to facilitate the technological uptake through training and advisory services, while underlining the believe in farmer-led agri-tech revolution and the role of cooperatives for driving the digital transformation of the sector (Copa-Cogeca, 2019).

On the other side of the agricultural equipment sector, the manufacturers expressed their vision about smartfarming pointing out data a technology enabler, both to improve production processes and decision support. In this case, smart agriculture technologies and equipment include guidance and positioning, sensing and control for variable rate application, telematics and data management, which are expected to support sustainable agriculture. Hence, they call the European policy to leverage the adoption of these agtech with dedicated measures and incentives (Dryancour, 2017).

In-between farmers and manufacturers, the dealers formalized their position in a paper about smart farming that focuses on machine to machine communication and data collection to improve design optimization, machinery settings and performances. Accordingly, they call for the update of dealers' training programs. Finally, the international dealers network call academy (research and education) to provide references and ideas for new business models based on digital data, pointed out as the glue across the agfood chain (CLIMMAR, 2018).

In summary, the agtech sector seems to evolve towards a split offer between products -i.e., the tangibles machines and equipment - and services based on equipment connection and data production and collection. Farmers and other agricultural operators acknowledge the relevance of agtech for precision farming, whilst calling to keep the development and mastery based on the agricultural savoir-faire. On their side, dealers and manufacturers appear to being willing to explore the provision of new services and to improve the equipment setup and development through data collection. Accordingly, the question arises concerning the knowledge required to understand and exploit the potential of the new generations of agtech and the associated challenges (Ritz et al., 2019).

\section{FOCUS ON AN EDUCATION AND TRAINING PLAYER IN FRENCH AGTECH}

France is the first Member State both for crops and livestock production, responsible for the $21 \%$ of the total European production. It is though only the third country for the agricultural equipment production, behind Germany and Italy (AXEMA, 2019). The agricultural equipment sector in France involves the same players mentioned for Europe (Figure 
2). Namely, dealers are intermediating between farmers and manufacturers. Following the agtech development, manufacturers are being sided by new players, partly external to the agricultural sector, specialized to the provision of data augmented equipment and services. France presents nevertheless some specificities on the farmers' side. For instance, farmers may share the equipment through dedicated cooperatives (e.g., CUMA) or platforms (e.g., Co-Farming and alike).

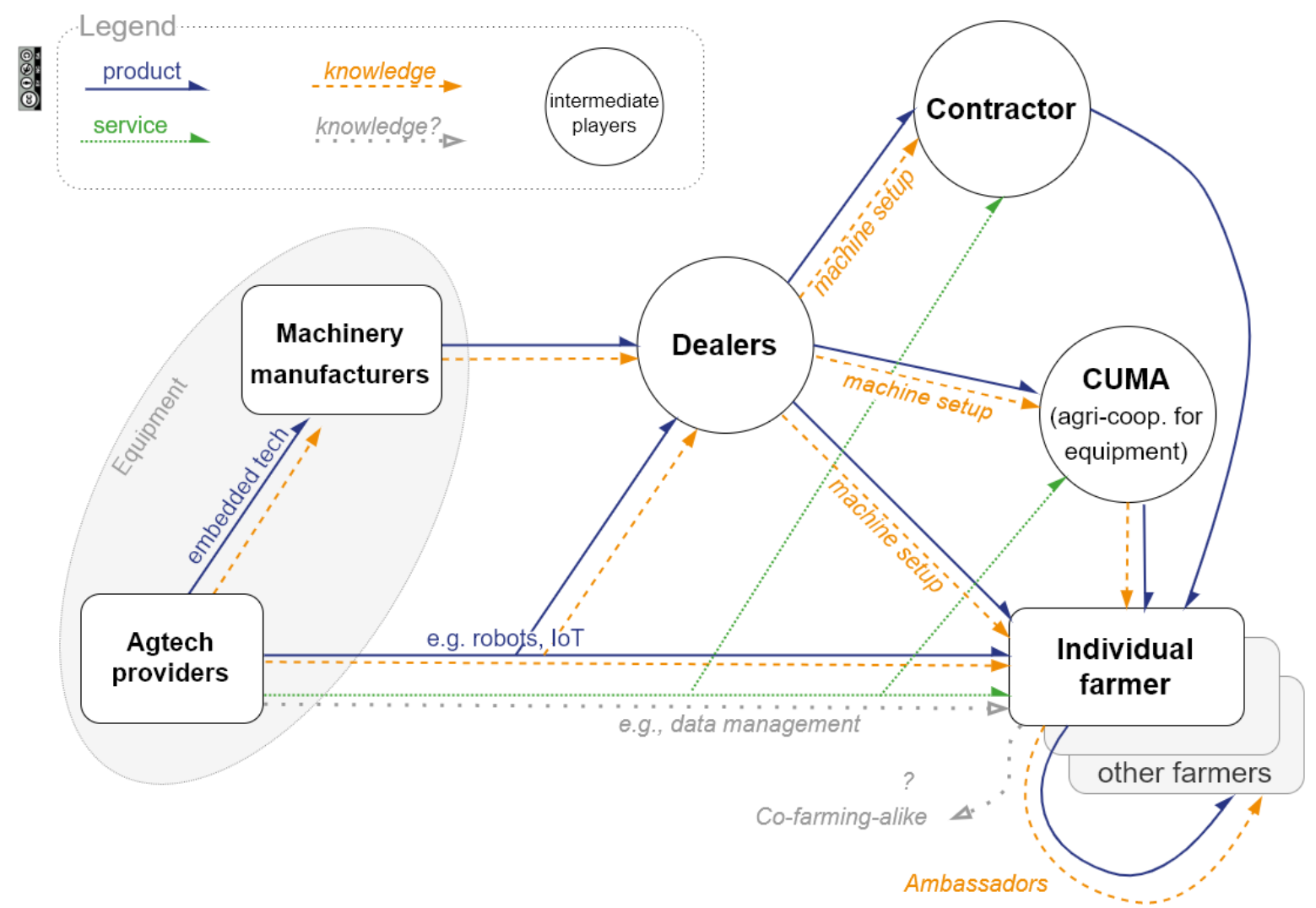

Figure 2. Schematic overview of the interactions between the key players in the agricultural equipment sector.

The development and provision of data augmented equipment could meet the French ambition of improving the position in the European and wider market of agricultural equipment. In this context, the Beauvaisis agglomeration community, placed in the Hauts-de- France (the French region with the largest share of utilized agricultural area) promoted in 2018 the creation of a cluster for agtech innovation and digital agriculture. It involves a tractor manufacturer, a transmission technology producer, a software producer, a technical institute for mechanics and two new players within academia (Rizzo et al., 2018).

The academia is hereby represented by the Polytechnical Institute UniLaSalle, one of the largest and oldest school in agronomy in France. The involvement of the higher education could indeed ease the evolution of educational and training programs thanks to the capabilities to propose and adapt engineering curricula to the need of the industry. Over the last ten years, four mains education and pedagogic reforms were deployed by the Polytechnical Institute UniLaSalle to improve the meeting of the different enterprises in the agricultural sector: (2010) a focus on a skills-based approach, (2013) the strengthening of the inductive teaching (learning by doing), especially for the apprentice training, whose track was separated from those of full-time students; (2016) internationalization of the curriculum, namely through a whole semester internship in other universities of the international Lasallian network (IALU); finally (2019) the design of a brand-new modular system enabling students to draw their educational curriculum according to the evolutive needs of recruiter and enterprises, finally strengthening the skill-based approach introduced in 2010. Nevertheless, in the current educational landscape, the intermediate players recruit principally at the medium level (upper secondary and postsecondary non-tertiary education). The renewal at this level could benefit from the innovation at the higher level presented before. In particular, new engineering curricula may support the reflection of the public bodies (i.e., Ministry for Education) in charge of the educational technical programs.

The improvement of the agricultural and engineering curricula to support the agtech development and deployment is also recommended by the French report about the agricultural equipment sector; in particular there is the call to bring training closer to the farmers' and manufacturers' needs (Bournigal, 2014, p. 110). In this vein, other official reports insist on the opportunity to develop agricultural living labs and network including farmers and agtech developers (Bournigal et al., 2015, p. 44; Machenaud et al., 2014, pp. 37-38) inspired, for instance, to the European ICT and robotics for sustainable agriculture ERA-Net programs (Villani, 2018, p. 206). Several examples confirm the relevance of agtech players to explore the definition of agronomic references in the setup, use and exploitation of data augmented equipment (e.g., the 
agricultural robotics association RobAgri, the pioneer farmers' network "Fermes Leaders, the network of fully agtech farms "DigiFermes" coordinated by ARVALIS, etc.).

\section{RECOMMENDATIONS AND CONCLUSION}

The renewal of the farmers population on top of the availability of embedded and connected sensors and advanced technologies open the way and need for new farming systems and models, whose design will shift the focus from the adaptation of the agrosystem to selected crop/breeding to the performance optimization of farming practices as function of the agrosystem characteristics and potential. In this vein, new farming systems are being drawn upon data augmented decision systems and practices, freeing farmers from routine operations thus leaving room for the development and deployment of their knowledge based on the field observation.

In conclusion, it clearly emerges the relevance for the co-design of agtech at the junction between life sciences, classical engineering and data science (Damave, 2017; Villani, 2018, p. 209), extending to agriculture what is being developed in the bioengineering and biomechanics sectors. Accordingly, we recall the need for the evolution of educational programs both at the secondary and tertiary levels. Considering the different development times that they have, we suggest the creation of hybrid curricula and ongoing vocational training programs addressing the needs of intermediate players.

Agtech are promising to solve sustainability issues of agriculture, but new skills are required to embed them into the evolving farming models and systems. Who will define this new knowledge and its value?

Acknowledgements. This work has been supported by Chair in Agricultural Machinery and New Technologies, backed by Institut Polytechnique UniLaSalle with the financial support from the Michelin Corporate Foundation, AGCO Massey-Ferguson, Kuhn, the Hauts-de-France Regional Council and the European Regional Development Fund (ERDF). The first author was supported by the Lithuanian Science Council that financed the travel and accommodation costs as invited keynote speaker.

\section{REFERENCES}

1. AXEMA, 2019. Economic report 2018. AXEMA - Union de l'Industrie de l'Agroéquipement.

2. Bournigal J.-M., 2014. Définir ensemble le futur du secteur des agroéquipements (Rapport de la mission agroéquipements, Irstea).

3. Bournigal J.-M., Houiller F., Lecouvey P., Pringuet,P. 2015. Agriculture - Innovations $2025: 30$ projets pour une agriculture compétitive \& respectueuse de l'environnement (Rapport aux Ministres en charge de l'agriculture et en charge de la recherche). Ministère de l'Agriculture, de l'Agroalimentaire et de la Forêt, Paris (FRA).

4. CLIMMAR, 2018. Position paper on smart farming.

5. Cook E. European Commission, Statistical Office of the European Union, 2018. Agriculture, forestry and fishery statistics: 2018 edition. (No. KS-FK-18-001-EN-N). Eurostat.

6. Copa-Cogeca, 2019. Feeding Europe's future. Wefarm4Eu.

7. Damave M.-C., 2017. Tous acteurs de la transition numérique agricole. saf agr'iDées, Paris (FRA).

8. DG Agri, 2017. Future of CAP: What's cooking for the next CAP? | European Commission [WWW Document]. Agriculture and Rural Development EU Commission Department. URL https://web.archive.org/web/20190602002741/https:/ec.europa.eu/info/news/future-cap-whats-cooking-next-cap_en (accessed 10.9.19).

9. Dryancour G., 2017. Smart Agriculture for All Farms What needs to be done to help small farms access Precision Agriculture? How can the next CAP help? CEMA, European Agricultural Machinery Association.

10. Dubois M., Fourati-Jamoussi F., Dantan J., Rizzo D., Jaber M., Sauvee L. 2019. The Agricultural Innovation Under Digitalization, in: Mezghani, K., Aloulou, W. (Eds.), Business Transformations in the Era of Digitalization:, Advances in E-Business Research. IGI Global, pp. 276-303. https://doi.org/10.4018/978-1-5225-7262-6.ch015

11. Eurostat, 2017. Farmers in the EU - statistics - Statistics Explained [WWW Document]. URL https://web.archive.org/web/20190713004243/https://ec.europa.eu/eurostat/statistics-explained/index.php/Farmers_in_the_EU__statistics (accessed 10.9.19).

12. Kritikos M. 2017. Precision agriculture in Europe. Legal, social and ethical considerations (No. PE 603.207). European Parliamentary Research Service.

13. Kurrer C., Tarlton J. (Eds.), 2017. Ten more technologies which could change our lives: in-depth analysis.

14. Lioutas E.D., Charatsari C., La Rocca G., De Rosa M. 2019. Key questions on the use of big data in farming: An activity theory approach. NJAS - Wageningen Journal of Life Sciences 100297. https://doi.org/10.1016/j.njas.2019.04.003

15. Machenaud G., Klein P., Terrien F., Pasco E. 2014. Agroéquipement et triple performance. Freins et leviers pour la transition agroécologique. ABSO conseil.

16. Philippe D., Baptiste B., Emerence C., Ramy S. 2016. Agricultural cooperatives and digital technology. What are the impacts? What are the challenges? PwC.

17. Ritz S., Rizzo D., Fourati F., Dantan J., Combaud A., Dubois M. 2019. Training in agricultural technologies: a new prerequisite for smart farming, in: Sustainable Agriculture : An Opportunity for Innovation in Machinery and Systems. Presented at the 3rd Rendez-Vous Techniques AXEMA, AXEMA - EurAgEng, Villepinte (FRA), p. 11. 
18. Rizzo D., Fourati F., Ceapraz L., Ostapchuk M., Radrianasolo H., Combaud A., Jaber M., Dubois M. 2018. Identifying the actors' interactions within an agricultural innovation system towards sustainability. The case of a French cluster for agritech innovation., in: International Workshop on System Innovation towards Sustainable Agriculture. Presented at the SISA 3, Riga, Latvia.

19. Villani C.,2018. Donner un sens à l'Intelligence Artificielle. Mission parlementaire du 8 septembre 2017 au 8 mars 2018.

20. World Economic Forum, 2018. Innovation with a Purpose: The role of technology innovation in accelerating food systems transformation. World Economic Forum. 